\title{
INCIDENCE OF ACCESSORY PHRENIC NERVE AND ITS CLINICAL SIGNIFICANCE: A CADAVERIC STUDY
}

\author{
Soubhagya R. Nayak ${ }^{1}$, Ashwin Krishnamurthy ${ }^{1}$ Latha V. Prabhu ${ }^{1}$,Lakshmi Ramanathan ${ }^{1}$, Mangala M. Pai ${ }^{1}$, \\ Bhagath Kumar Potu', Srijit Das ${ }^{3}$
}

Kasturba Medical College, CBS, Bejai, Mangalore, Karnataka, India: Department of Anatomy ${ }^{1}$; Centre for Basic Sciences, Kasturba Medical College, Manipal University, Manipal, Karnataka, India: Department of Anatomy²; University Kebangsaan Malaysia, Kuala Lumpur, Malaysia: Department of Anatomy ${ }^{3}$

\begin{abstract}
Summary: The description of accessory phrenic nerve (APN) in the standard textbooks and available literature is vague and sometimes limited to few lines. The incidence of APN varies a great deal from $17.6 \%$ to $80.9 \%$ in the available literature. The aim of the present study was to calculate the incidence and variation of APN in Indian population. Material and methods: Forty five adult formalin-fixed cadavers (35 male, 10 female; 90 sides) used for gross anatomy dissection for undergraduates; during the 2 year period 2006-2007 were considered. Findings were recorded at different stages of the dissection. Results: Out of 90 body sides studied, the APN was present in 48 sides (53.3 \%). In 17 of the above sides the APN was confined to the cervical region (Cervical type) and in 31 sides the APN entered the thorax (Thoracic type), all anterior to the subclavian vein (SV). In eleven specimens the APN was found bilaterally. Conclusion: The incidence of APN, with its course and relation to the various structures in cervical and thoracic region will help the surgeons while performing internal thoracic artery (ITA) grafting and other radical neck surgery.
\end{abstract}

Key words: Accessory phrenic nerve; Incidence; Variation; Surgical significance.

\section{Introduction}

The accessory phrenic nerve (APN) is commonly a branch from the nerve to the subclavius. It lies lateral to the phrenic nerve and descends behind, or sometimes in front of, the SV. It joins the main nerve usually near the first rib or sometimes union may even below the root of the lung. The APN may occasionally arise from spinal nerves $\mathrm{C} 4$, or C6, or from the ansa cervicalis (10).

The incidence of the APN was varies a great deal in the available literature. Felix (Cited by Kikuchi) observed the APN in $17.6 \%$ population he studied (6), in contrast to him Kelly (Cited by Loukas et al.) mentioned the presence of APN in $80.9 \%$ cases (7). The APN may arise as additional roots from one or more of the following nerves: nerve to subclavius; nerve to sternohyoid; second or rarely, sixth cervical spinal nerves; descendens cervicalis; ansa cervicalis; and brachial plexus. It may receive a branch from hypoglossal and may communicate with spinal accessory. The size of the nerve may vary bilaterally (2). The present study was conducted to find out the occurrence of APN in Indian population and discussed its clinical significance.

\section{Material and Methods}

The anatomy of the APN was examined in forty five adult formalin-fixed cadavers ( 35 male, 10 female; 90 sides) used for gross anatomy dissection at the Kasturba Medical College, Mangalore for undergraduates during 2006 to 2007. The mean age of the cadavers was 58 years (range, 49 to 83 years). The cadavers had been fixed in $10 \%$ formalin solution. None of the specimens revealed any evidence of previous surgical procedures, traumatic lesions, or gross pathologies to the neck and thorax. Findings of the dissection were recorded at different stages of the dissection. The nerves contributing to the phrenic nerve (PN) after it had crossed the scalene anterior muscle (SAM) considered being APNs. When the APN joined the PN above the level of first rib it was considered cervical type and when below the level of first rib it was considered as a thoracic type of APN.

\section{Results}

The PN was found bilaterally in all 45 cadavers (90 PNs) and an APN was present in 48 sides (53.3\%), 
with bilateral occurrence in 11 cadavers $(24.4 \%)$. In 17 of the above sides $(18.8 \%)$ the APN was confined to the cervical region (Cervical type) and in 31 sides (34.4\%) the APN entered the thorax (Thoracic type), all anterior to the $\mathrm{SV}$. The origin of APN varied widely from $\mathrm{C} 1$ root to $\mathrm{C} 6$ root of the brachial plexus (Table 1).

The most frequent origins of the APN were from the nerve to subclavius in 22 sides $(45.8 \%)$, supraclavicular nerve in 8 sides $(16.6 \%)$, ansa cervicalis in 8 sides $(16.6 \%)$ (Figs. 1, 2), upper trunk in 6 sides (12.5\%) (Fig. 3), from the $\mathrm{C} 5$ root in 4 sides $(8.3 \%$ ) (Fig. 4) (Tab. 1). In one of the case the APN took origin by two roots from the upper trunk (Fig. 3). The APN formed a loop with the PN after passing in front of the SV in all the cases in the present study (64.5\%) (Fig. 4). The above loop didn't involve any of the ITA. In the cervical type of APN, we also found an APN/PN loop around the subclavian artery (SA) (Fig. 5) and transverse cervical artery (Fig. 3) in one instances each. In all the above cases the APN was placed lateral to the PN.

\section{Discussion}

The frequency of variation in origin, course and communication between the PN and APN in our study differs widely from previous reports. Previous descriptions of APN frequency also vary considerably between the available lite- ratures (Tab. 2). The incidence of $53.3 \%$ of APN in the present study agrees closely with the result of Banneheka (1) and Loukas et al. (7) (Tab. 2). The lowest frequency for APN of $17.6 \%$ was reported by Felix (Cited by Kikuchi) (6) and the maximum for the same was $80.9 \%$ reported by Kelly (Cited by Loukas et al.) (7). Although several other authors too, have documented a wide range of frequencies for the APN a direct comparison with such results is of little or no validity because their definition of APN (1).

In the present study we considered all nerves as APN which was contributing to the PN after it had crossed the SAM, as described by Loukas et al. (7). The nerve to the subclavius was the major source of origin for the APN in the present study ( $45.8 \%$ cases) in compare to the $60.6 \%$ and $75 \%$ cases described by Loukas et al. (7) and Banneheka (1) respectively. The ansa cervicalis and supraclavicular nerve are the next most common origins of an APN. In the present study we didn't found APN taking origin from the nerve to sternohyoid, $\mathrm{C} 3$ root, $\mathrm{C} 4$ root, accessory nerve or hypogossal nerve as reported by Loukas et al. (7).

In the present study the APN was placed lateral to the $\mathrm{PN}$ in all the specimens as reported in Gray's Anatomy (10). In contrast to the above reports, Loukas et al. found APN descending medial to the PN in $9.1 \%$ specimens (7). In the present study the APN traveled anterior to the SV in all the 31 cases of thoracic type of APN (34.4\%) much si-

Tab. 1: Origin of the accessory phrenic nerve from various nerve components in the present study.

\begin{tabular}{|l|c|c|c|c|}
\hline Nerve Components & $\begin{array}{c}\text { Right } \\
\text { Side }\end{array}$ & $\begin{array}{c}\text { Left } \\
\text { Side }\end{array}$ & Total & $\begin{array}{c}\text { Incidence } \\
(\%)\end{array}$ \\
\hline Nerve to subclavius (C5 and C6) & 10 & 12 & 22 & 45.8 \\
\hline Upper trunk (C5 and C6) & 2 & 4 & 6 & 12.5 \\
\hline C5 & 2 & 2 & 4 & 8.3 \\
\hline Supraclavicular Nerve (C3 and C4) & 2 & 6 & 8 & 16.6 \\
\hline Ansa cervicalis & 4 & 4 & 8 & 16.6 \\
\hline Total & 20 & 28 & 48 & 100 \\
\hline
\end{tabular}

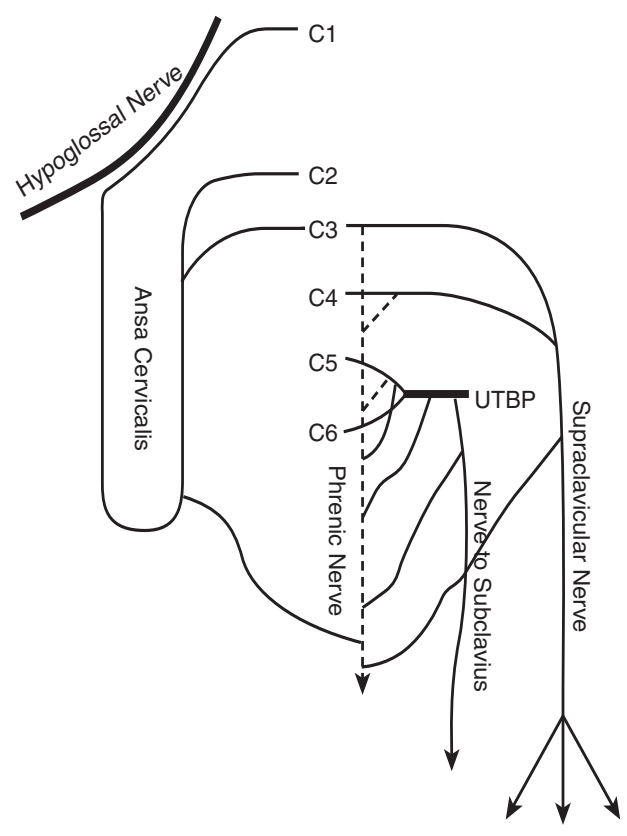

Fig. 1: Schematic diagram illustrates the different points of origin of the accessory phrenic nerve in the present study. These are 1, C5 nerve root; 2 , upper trunk of brachial plexus; 3 , nerve to subclavius; 4 , supraclavicular nerve; 5 , ansa cervicalis. The dashed lines forms the phrenic nerve. 


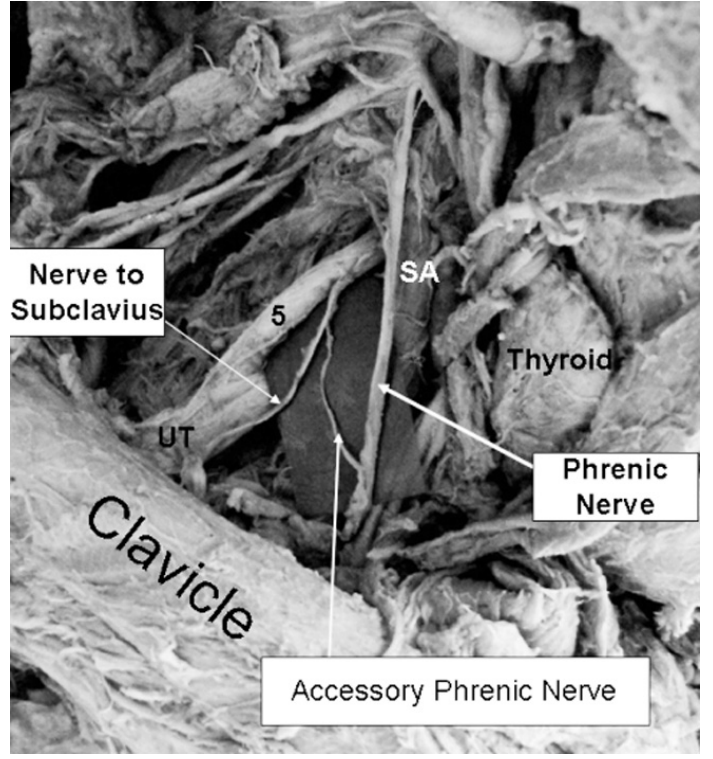

Fig. 2: Left side of the neck region. The communication of the accessory phrenic nerve with the phrenic nerve in the root of the neck (Cervical type). 5, fifth cervical nerve; SA, scalene anterior muscle; UT, upper trunk of brachial plexus.

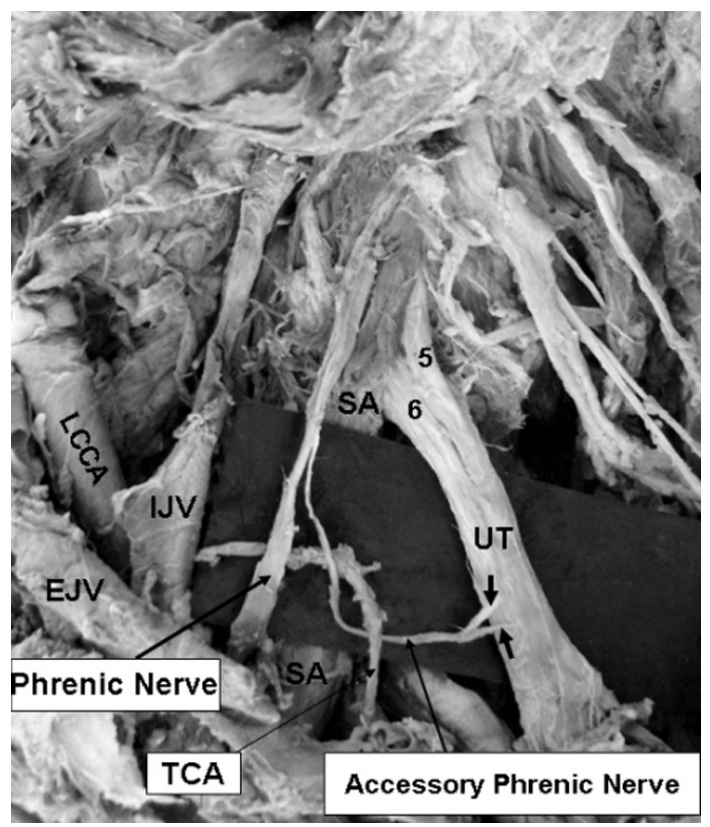

Fig. 3: Right side of the neck region. The communication of the accessory phrenic nerve with the phrenic nerve in the root of the neck forming a loop around the transverse cervical artery. 5 , fifth cervical nerve; 6 , sixth cervical nerve; EJV, external jugular vein; IJV, internal jugular vein; LCCA, left common carotid artery; SA, scalene anterior muscle; TCA, transverse cervical artery; UT, upper trunk of brachial plexus. Note the arrows indicate the accessory phrenic nerve taking origin from the upper trunk of brachial plexus by two roots.

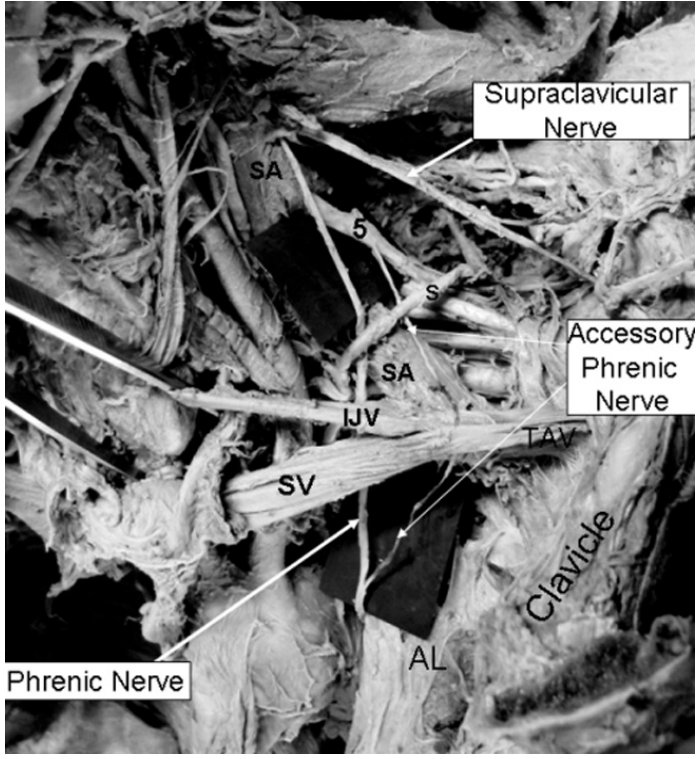

Fig. 4: Right side of the neck region. The communication of the accessory phrenic nerve with the phrenic nerve in the thorax (Thoracic type) forming a loop anterior to the subclavian vein. 5, fifth cervical nerve; AL, apex of lung; IJA, internal jugular vein; S, Suprascapular artery; SA, scalene anterior muscle; SV, subclavian vein; TAV, thoraco-acromial vein. Note the accessory phrenic nerve passing below the thoraco-acromial vein and above the subclavian vein.

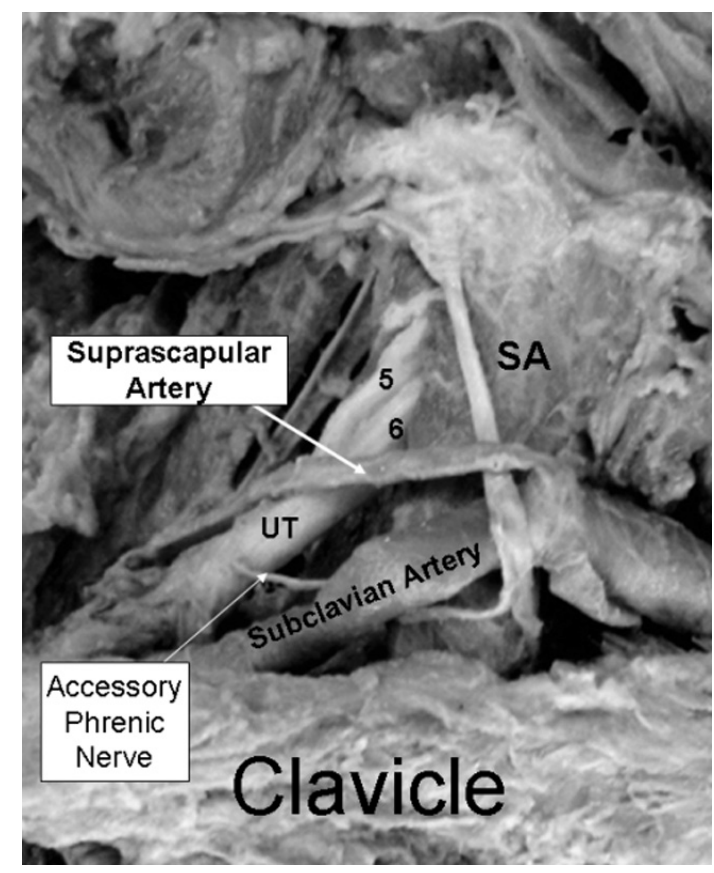

Fig. 5: Left side of the neck region. The communication of the accessory phrenic nerve with the phrenic nerve in the root of the neck forming a loop around the subclavian artery. 5 , fifth cervical nerve; 6 , sixth cervical nerve; SA, scalene anterior muscle; UT, upper trunk of brachial plexus. 
milar to the study conducted by Talbot (11), he reported the above occurrence in $45 \%$ cases. Banneheka considered the nerves that pass anterior to the SV to communicate with the principal PN as APN and any other nerve that communicates with the principal $\mathrm{PN}$ by passing posterior to the SV is designated as a secondary phrenic nerve (SPN) (1). He observed the incidence of so called SPN in 40 sides (19.4\%). Loukas et al. found the SPN in the $22.2 \%$ cases (7). We didn't observe a single case of SPN in the present study similar to the study conducted by Talbot (11).

Setina et al. described the importance of the relation between PN and in ITA during coronary artery bypass grafting (CABG) (9). The relationship between ITA and PN in the superior thoracic aperture is very variable. The ITA is now being used with increasing frequency for $\mathrm{CABG}$, because of its superior long-term patency compared with the saphenous vein grafts. The close anatomic relationship between ITA with the PN at the superior thoracic aperture can cause injury to the PN in coronary artery revascularization surgery (12). According to Loukas et al. the presence of an APN may increase the risk associated with any injury to PN (7). They also mentioned mobilization and skeletonization of the ITA above the second rib may damage the blood supply of the APN or sever its connection with the PN. In the present study we observed the APN being close to the ITA in $34.4 \%$ cases, although none of the cases APN/PN had a loop around the ITA. While avulsing the PN to immobilize the diaphragm, if it is a part of an APN/PN loop, it may damage the SV (4). In the present study such loop was observed in $34.4 \%$ cases and surprisingly an APN/PN loop was observed involving subclavian artery.

Bigeleisen (2003) reported that a supraclavicular block performed for ulnar osteotomy and ulnar nerve transposition resulted in twitching of diaphragm along with motor response in forearm (3). This is due to direct stimulation of the patient's PN. The author claims, this is due to the contribution to PN from nerve to subclavius arises in close proximity to the site where supraclavicular block is performed. Thus, when one considers the relatively high frequency of an APN or a branch from the brachial plexus itself, there is a significant possibility of anaesthetizing only part of the PN with a supraclavicular block. Due to the above fact it is necessary to have a thorough knowledge of the anatomical variations of APN for safe and efficient practice of regional anaesthesia.

\section{Conclusion}

Although knowledge regarding APN is necessary to deal with various surgical procedures in the thorax and root of the neck, unfortunately the description of APN in the medical text books is vague. The frequency and variable origin of APN in the present study will help surgeons and clinicians while dealing with the APN and PN, especially during ITA grafting and similar surgical interventions.

\section{References}

1. Banneheka S. 2008. Morphological study of the ansa cervicalis and the phrenic nerve. Anat Sci Int 2008;83:31-44.

2. Bergman RA, Thompson SA, Afifi AK, Saadeh FA. Compendium of human anatomic variation. Baltimore, Urban and Schwarzenberg. 1988;138-9.

3. Bigeleisen PE. Anatomical variations of the phrenic nerve and its clinical implication for supraclavicular block. Br. J. Anaesth. 2003;91:916-7.

4. Clemente CD. The peripheral nervous system. Chapter 12: spinal nerves. Gray's anatomy, $30^{\text {th }}$ ed. Baltimore: Williams \& Wilkins, 1985 p.1085

5. Fazan VPS, Amadeu ADS, Caleffi AL, Filho OAR. Brachial plexus variations in its formation and main branches. Acta Cir Bras 2003;18 (suppl. 5): 14-8.

6. Kikuchi T. A contribution to the morphology of the ansa cervicalis and the phrenic nerve. Kaibogaku Zasshi 1970;45:242-81.

7. Loukas M, Kinsella CR Jr, Louis RG Jr, Gandhi S, Curry B. Surgical anatomy of the accessory phrenic nerve. Ann Thorac Surg 2006;82:1870-5.

8. Matsumura H, Kumaki K. Morphogenesis of the subclavian vein relative to the course of the nerve to the subclavius muscle and the phrenic nerve. Acta Med Biol 1996;44:13-8.

9. Setina M, Cerny S, Grim M, Pirk J. 1993. Anatomical interrelation between the phrenic nerve and the internal mammary artery as seen by the surgeon. J Cardiovasc Surg 1993;34:499-502.

10. Standring S. Chapter 31: neck; Gray's Anatomy, $39^{\text {th }}$ ed. Edinburgh: Elsevier, Churchill Livingstone, 2005 p. 555.

11. Talbot RW. Anatomical pitfall of subclavian venepuncture. Ann R Coll Surg Engl 1978;60:317-19.

12. Yener N, Sargon MF. Interrelation between the internal thoracic artery and phrenic nerve in the superior thoracic aperture. Gazi Medical Journal 1998;9: $57-60$.

\section{Corresponding author:}

Soubhagya R. Nayak, Department of Anatomy, Centre for Basic Sciences, Kasturba Medical College, Bejai, Mangalore-575004, Karnataka, India; e-mail: ranjanbhatana@gmail.com 